\title{
Analytical and Stability Studies on Medical Cosmetics
}

\author{
Manal I. Eid*, Mary E. K. Wahba \\ Department of Analytical Chemistry, Faculty of Pharmacy, Mansoura University, Mansoura, Egypt \\ Email: *manal_eid@yahoo.com
}

Received August 11, 2011; revised September 28, 2011; accepted October 8, 2011

\begin{abstract}
Two simple and sensitive spectrofluorimetric (method I) and spectrophotometric (method II) methods have been developed for the determination of some chloride containing toothpastes and panthenol-containing cosmetic preparations respectively. Method I is based on quantitative fluorescence quenching of (terbium-salicylate-hexamine ternary complex) by fluoride which could be measured at $\lambda_{\mathrm{em}} / \lambda_{\mathrm{ex}}$ of $547 \mathrm{~nm} / 322 \mathrm{~nm}$. The $\Delta \mathrm{F}$-concentration plot was rectilinear over the concentration range of $0.5-20 \mu \mathrm{g} / \mathrm{ml}$. Method II depends reaction of panthenol with nitrobenzoxadiazole chloride (NBD-Cl) and measuring the absorbance of the resultant product at $480 \mathrm{~nm}$. The absorbance-concentration plot was rectilinear over the concentration range of $2-20 \mu \mathrm{g} / \mathrm{ml}$.
\end{abstract}

Keywords: Panthenol; Spectrophotometry; Spectrofluorimetry; Stability Studies

\section{Introduction}

Panthenol (Figure 1) is one of the components of some local cosmetic preparations. The USP [1] stated a non aqueous titration method for its determination. Despite the low molecular absorptivity of panthenol due to the lack of UV chromophores, yet direct spectrophotometric assay has been reported [2]. Several colorimetric analysis have been reported for the determination of panthenol after its hydrolysis [3,4]. As an alcohol, panthenol has been determined by gas liquid chromatographic method [5-7]. Liquid chromatographic methods either directly $[8,9]$ or after derivatization and condensation with fluorescamine [10] was also used for assay of panthenol. Thin layer chromatographic determination of panthenol with spectrodensitometric detection was also mentioned in the literature [11]. The use of $\mathrm{H}^{1} \mathrm{NMR}$ for the analysis of panthenol in mixtures has also been published [12]. Fluorimetric methods for panthenol after its hydrolysis to $\beta$ alanol and reaction with either ninhydrin or NBD-Cl were also reported [13].

Fluoride, like other halides, is a monovalent ion, which is a major ingredient in many toothpaste preparations. Literature review reveals that fluoride was determined by spectrophotometry [14-18], spectrofluorimetry [19], and voltammetry [20].

In this work, fluoride was determined in many of its commercial toothpastes applying spectrofluorimetry [19]. Moreover, the present work is trying to present a stability indicating assay of some lotions and creams containing panthenol using a reported method [13] as a guide; which

\footnotetext{
${ }^{*}$ Corresponding author.
}

depends on the fact that NBD-Cl is a fluorigenic agent specific for primary amino group, which is a result of the alkaline hydrolysis of panthenol to $\beta$ alanol. Since panthenol by itself, does not contain a primary amino group, it is supposed that it will not react with NBD-Cl without hydrolysis, which was used in this work as a basic concept to estimate the stability of panthenol in its local cosmetic preparations.

This research focused on the application of stability studies to determine some cosmetic preparations depending on the high consumption of such products in the local market of our community, and counting on the fact that such products may undergo physical or chemical degradation as a result of inappropriate storage. So we tried in our laboratory to predict the best conditions for highest stability of such products to achieve better storage and hence consumer compliance. We have chosen spectrofluorimetry and spectrophotometry to access this purpose, due to their simplicity and high sensitivity, in addition to their availability in most laboratories which facilitates the use of the proposed method in quality control laboratories.

\section{Experimental Procedures}

\subsection{Apparatus}

1) Spectrophotometric analyses were carried out on a Dynamica Halo DB-20 spectrophotometer; UV-Visible double-beam spectrophotometer with matched $1 \mathrm{~cm}$ path-length quartz cells. Absorption spectra of the studied drug were recorded on a fast scan speed, setting slit 
<smiles>CC(C)(CO)[C@@H](O)C(=O)NCCCO</smiles>

Figure 1. Structural formula of panthenol.

width to be $1 \mathrm{~nm}$ and sampling interval to be auto.

2) Spectrofluorometer: Perkin Elmer LS 45 Luminescence Spectrometer, equipped with a $150 \mathrm{~W}$ Xenon arc lamp, grating excitation and emission monochromators, and a recorder. Slit widths for both monochromators were set at $10 \mathrm{~nm}$. A $1 \mathrm{~cm}$ quartz cell was used. Derivative spectra were evaluated using Fluorescence Data Manager (FLDM) software, Perkin Elmer Buck i.e. FL WINLAB, version 400.02 .

\subsection{Materials and Reagents}

1) NBD-Cl (Aldrich Chemical Co., Ltd., Dorset, England) was freshly prepared by dissolving $5 \mathrm{mg}$ in $50 \mathrm{ml}$ volumetric flask using ethanol. The solution is made to volume with the same solvent to get a solution of a final concentration of $100 \mu \mathrm{g} / \mathrm{ml}$.

2) Borate buffer of $\mathrm{pH} 8$ was prepared by mixing 0.2 $\mathrm{M}$ boric acid and $0.2 \mathrm{M}$ sodium hydroxide.

3) Ammonium fluoride (Riedel dehaen, Sleeze, Germany), a stock solution of concentration $0.5 \mathrm{mg} / \mathrm{ml}$ was prepared by dissolving $0.025 \mathrm{~g} \mathrm{NH}_{4} \mathrm{~F}$ in $50 \mathrm{ml}$ volumetric flask using distilled water, and completing to the mark with the same solvent. This solution was further diluted to contain $12.5-500 \mu \mathrm{g} / \mathrm{ml}$ of fluoride in a series of $25 \mathrm{ml}$ volumetric flasks.

4) Terbium chloride (Aldrich Chemical Co., Ltd., Dorset, England), working solution of $4 \times 10^{-3} \mathrm{M}$ was prepared by diluting the stock $0.08 \mathrm{M}$ solution.

5) Hexamine (El Nasr Pharmaceutical Company, Egypt), was prepared as $10 \% \mathrm{w} / \mathrm{v}$ and its $\mathrm{pH}$ was adjusted to 8.5 with $0.2 \mathrm{M}$ sodium hydroxide.

6) Sodium salicylate (El Nasr Pharmaceutical Company, Egypt), was prepared as $7 \times 10^{-3} \mathrm{M}$ in distilled water.

7) The cosmetic preparations include:

Toothpastes containing fluoride:
a) Signal 2
b) Close up
c) B-fresh
d) Colgate
e) Miswak

Cosmetic preparations containing panthenol:
a) Panthenol cream
b) Panthenol lotion
c) Pantho EVA gel
d) Acopantin cream

\subsection{Construction of the Calibration Curve for Method I}

To each $25 \mathrm{ml}$ volumetric flask, add $1 \mathrm{ml}$ of $\mathrm{TbCl}_{3}$ solution $\left(4 \times 10^{-3} \mathrm{M}\right), 1 \mathrm{ml}$ of sodium salicylate solution $(7 \times$ $\left.10^{-3} \mathrm{M}\right), 1 \mathrm{ml}$ of hexamine $10 \%$ solution previously adjusted to $\mathrm{pH}$ 8.5. To each flask, transfer $1 \mathrm{ml}$ aliquots of fluoride solutions so that the solutions contain 0.5 to 20 $\mu \mathrm{g} / \mathrm{ml}$ fluoride. A blank was made by adding $1 \mathrm{ml}$ of sodium salicylate solution $\left(7 \times 10^{-3} \mathrm{M}\right)$ into $25 \mathrm{ml}$ volumetric flask. The flasks are then filled up with distilled water. The fluorescence intensities of the solutions are measured at $547 \mathrm{~nm}$ after excitation at $322 \mathrm{~nm}$. A plot of the difference in fluorescence intensity against the concentration of the fluoride added is thus made to obtain the standard calibration graph (Figure 2). Alternatively, the linear regression equation was derived.

\subsection{Construction of the Calibration Curve for Method II}

One gram of the cream or gel is grind with $1 \mathrm{gm}$ of anhydrous sodium sulphate and dissolved in few milliliters of distilled water, filtered if necessary. The solution is then brought to $50 \mathrm{ml}$ with distilled water. Aliquot volumes of the prepared preparations covering the concentration range of $2-20 \mu \mathrm{g} / \mathrm{ml}$ were transferred into a series of $10 \mathrm{ml}$ volumetric flasks, $3 \mathrm{ml}$ of borate buffer $\mathrm{pH}$ 8 , followed by $2 \mathrm{ml}$ of NBD-Cl were added, then the solutions are placed in a boiling water bath for $15 \mathrm{~min}$ utes. The solutions are cold, and made to volume with distilled water. The absorbance readings of the resultant solutions are measured at $480 \mathrm{~nm}$. Base line correction was carried out to delete any absorbance reading of the blank. The measured absorbance values were plotted against the final concentration of the drug $(\mu \mathrm{g} / \mathrm{ml})$ to get the calibration curve (Figure 3). Alternatively, the corresponding regression equation was derived.

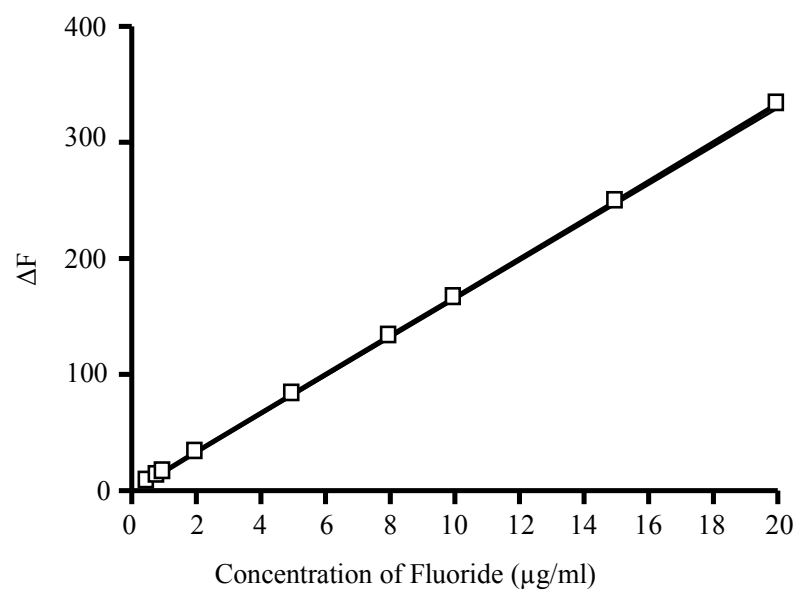

Figure 2. Calibration curve for fluoride applying the reference method. 


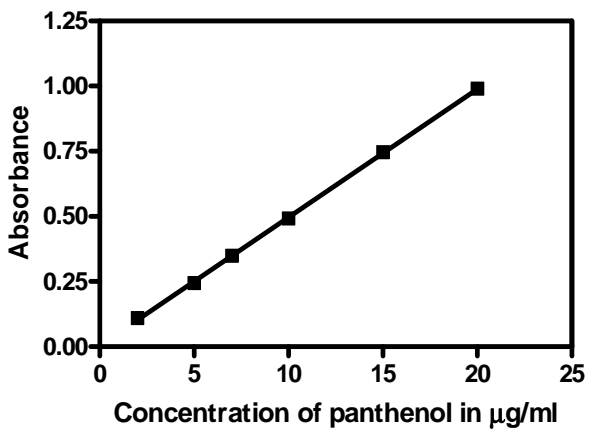

Figure 3. Calibration curve for panthenol applying the reference method.

\section{Results and Discussion}

Fluoride was quantitatively assayed through its quenching of the fluorescence of a ternary complex of terbiumsalicylate-hexamine. The different experimental parameters affecting the intensity of the ternary complex were carefully studied and incorporated into the procedure. The method was successfully applied for the determination of fluoride ion in toothpastes.

Panthenol stability was estimated through is reaction with NBD-Cl without hydrolysis. Different experimental parameters affecting the formation of the reaction product were carefully studied and optimized. Such factors were changed individually while the others were kept constant.

\subsection{Effect of Different Temperature Settings}

The reaction was carried out at different temperature settings (room temperature, $60^{\circ} \mathrm{C}, 70^{\circ} \mathrm{C}, 80^{\circ} \mathrm{C}, 90^{\circ} \mathrm{C}$, $100^{\circ} \mathrm{C}$ ) using a thermostatically controlled water bath. It was found that the absorbance readings increase gradually by increasing the temperature to be maximum by boiling (Figure 4). This could be explained that the higher the temperatures are, the more the drug undergoes degradation and hence starts to react with NBD-Cl giving higher absorbance reading.

\subsection{Effect of Reaction Time}

The effect of reaction time between panthenol and NBD$\mathrm{Cl}$ was investigated over the period of (5 - 60 minutes), the absorbance values increase gradually by the increase in the reaction time (Figure 5). These results are expected since longer boiling times expose panthenol to be degraded more than short times, which in turn increases its ability to react with NBD-Cl.

Semilogarithmic plots of panthenol at different temperature settings after the addition with $\mathrm{NBD}-\mathrm{Cl}$ was studied (Figure 6), The first order degradation rate constant and the half life time at each temperature were calculated according to the following equations: $\ln \mathrm{a} / \mathrm{a}-\mathrm{x}=\mathrm{Kt}$

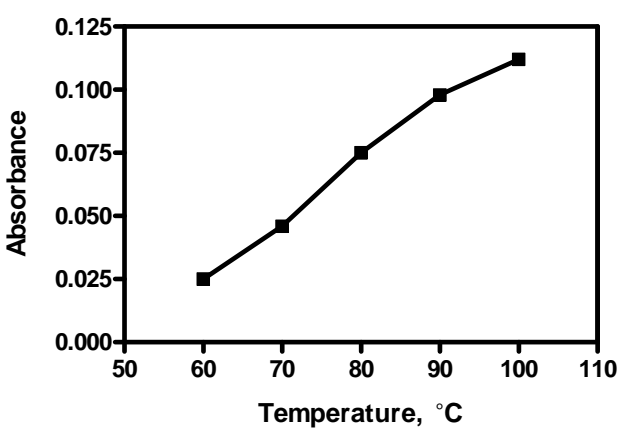

Figure 4. Effect of different temperature settings on the absorbance readings of panthenol.

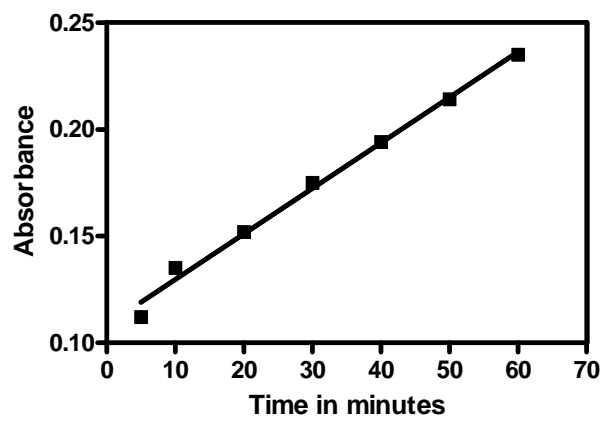

Figure 5. Effect of time on the absorbance readings of panthenol.

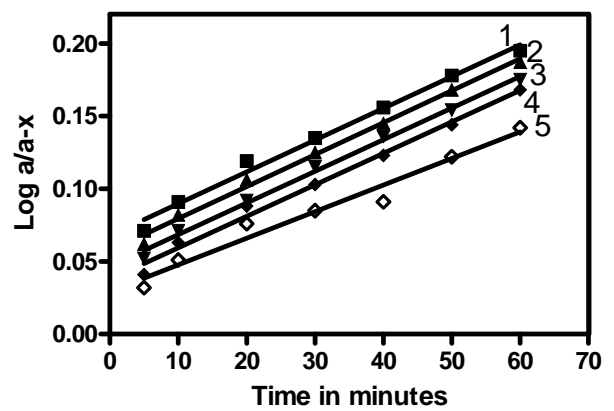

Figure 6. Semi logarithmic plot of panthenol at different temperatures. Where 1) $100^{\circ} \mathrm{C}$; 2) $80^{\circ} \mathrm{C}$; 3) $70^{\circ} \mathrm{C}$; 4) $60^{\circ} \mathrm{C}$; 5) $40^{\circ} \mathrm{C}$.

where $\mathrm{a}$ is the initial concentration of the drug, $\mathrm{x}$ is the concentration of the resulting degraded solution after time $\mathrm{t}$, and $\mathrm{K}$ is the reaction rate constant, while the half life time $\left(\mathrm{t}_{1 / 2}=0.693 / \mathrm{K}\right)$.

The results obtained illustrated that panthenol is of high stability since it doesn't react with the reagent except after is alkaline degradation to produce the primary amino group responsible for the reaction with NBD-Cl. Maximum stability was achieved after 5 minutes at $40^{\circ} \mathrm{C}$.

This method was also extended to study the stability of panthenol at different percentages of humidity at different time intervals (Figure 7). Maximum stability of panthenol was attained at $15 \%$ of humidity for 6 months which should be considered in the storage parameters. 


\subsection{Pharmaceutical Applications}

The proposed methods were successfully applied for the determination of fluoride (Table 1) and panthenol (Figure 8) in their different cosmetic preparations.

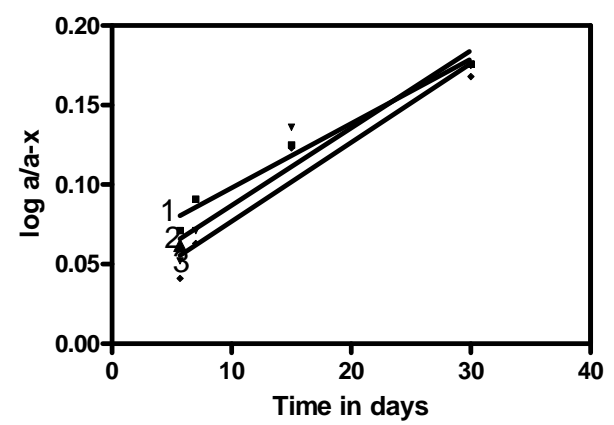

Figure 7. Semi logarithmic plot of panthenol at different \% humidity. Where 1) $95 \%$; 2) $40 \%$; 3) $15 \%$ relative humidity.

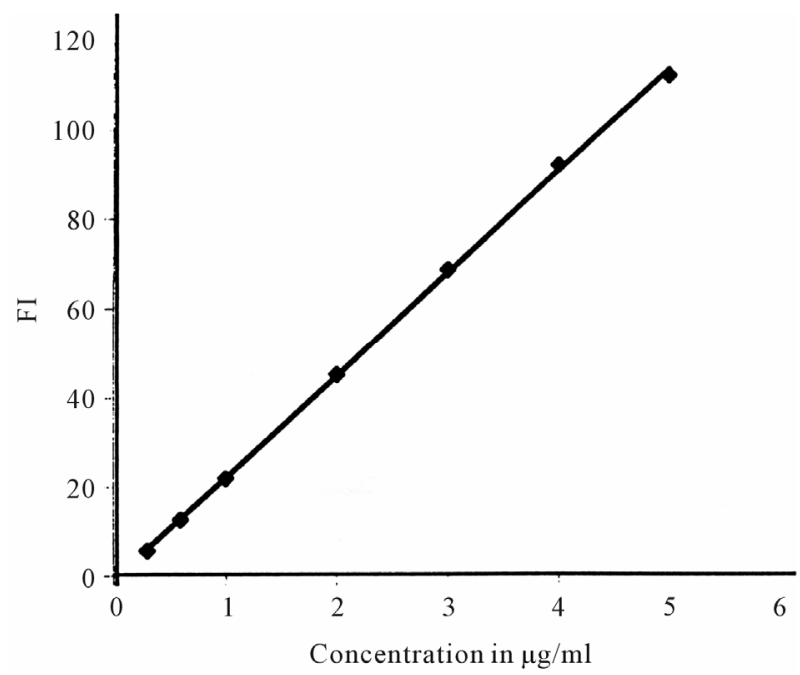

Figure 8. Calibration curve for panthenol cream.

Table 1. Application of the reference method for determination of fluoride in toothpastes.

\begin{tabular}{|c|c|c|c|c|}
\hline \multirow{2}{*}{$\begin{array}{r}\text { Dosage } \\
\text { Forms }\end{array}$} & \multicolumn{2}{|c|}{ Colgate $^{1}$} & \multicolumn{2}{|c|}{ Crest $^{2}$} \\
\hline & Proposed & Ref. & Proposed & Ref. \\
\hline \multirow{3}{*}{$\%$ Recovery } & 99.200 & 99.600 & 99.800 & 99.900 \\
\hline & 99.400 & 99.500 & 99.400 & 99.800 \\
\hline & 99.700 & 100.100 & 100.000 & 100.100 \\
\hline Mean $\left(\mathrm{x}^{-}\right)$ & 99.433 & 99.733 & 99.733 & 99.933 \\
\hline \pm S.D. & 0.25 & 0.32 & 0.30 & 0.15 \\
\hline Variance & 0.06 & 0.10 & 0.09 & 0.02 \\
\hline Students $t$-value & \multicolumn{2}{|c|}{1.280} & \multicolumn{2}{|c|}{1.026} \\
\hline $\begin{array}{l}\text { Variance ratio } \\
F \text {-value }\end{array}$ & \multicolumn{2}{|c|}{1.635} & \multicolumn{2}{|c|}{4.043} \\
\hline
\end{tabular}

\section{Conclusion}

Two simple and sensitive spectrofluorimetric and spectrophotometric methods have been developed for the determination of some cosmetic preparations. Stability studies were conducted to predict the best conditions for storage of the studied compounds. The simplicity of the proposed methods allows their applications in quality control laboratories.

\section{REFERENCES}

[1] "The United States Pharmacopoeia 30, the National Formulary 25," US Pharmacopeial Convention," Rockville, 2007.

[2] W. Thies, "Direct Spectrophotometric Measurements on Sodium Citrate and Panthenol Solutions," Pharmazie, Vol. 50, 1983, pp. 487-488.

[3] D. Bertini, V. Nuti and G. Linari, "Quantitative Determination of Compounds Present in a Pharmaceutical Preparation (Antiseborrhoeic shampoo)," Bollettino Chimico Farmaceutico, Vol. 121, 1982, pp. 535-544.

[4] M. Shehata, S. Tawakkol and L. A. Fattah, "Colorimetric and Fluorimetric Methods for Determination of Panthenol in Cosmetic and Pharmaceutical Preparations," Journal of the Pharmaceutical Biomedical Analysis, Vol. 27, No. 5, 2002, pp. 729-735. doi:10.1016/S0731-7085(01)00510-6

[5] A. Takasu and K. Oyha, "Separation and Determination of the Enantiomers of Pantolactone by Gas-Liquid Chromatography," Journal of Chromatography, Vol. 389, No. 1, 1987, pp. 251-255. doi:10.1016/S0021-9673(01)94430-9

[6] W. A. Koening and V. Sturm, "Determination of Optical Purity by Enantioselective Capillary Gas Chromatography; Panthenol and Relative Compounds," Journal of Chromatography, Vol. 328, 1985, pp. 357-361. doi:10.1016/S0021-9673(01)87409-4

[7] V. S. Slyshenko and A. G. Moiseenok, "Gas Chromatographic Determination of Pantothenic Acid (Derivatives) in Vitamin Containing Preparations," Khimko Farmatsevticheskii, Vol. 17, 1983, pp. 1513-1516.

[8] K. D. Altria, "Background Theory and Application of Microemulsion Electrokinetic Chromatography," Journal of Chromatography, Vol. 892, No. 1-2, 2000, pp. 171186. doi:10.1016/S0021-9673(00)00088-1

[9] R. K. Gharehbagh and S. Ebel, "Stability Analysis of Dexpanthenol. 1-Determination of Dexpanthenol and Pantolactone by HPLC," Pharmazie, Vol. 50, No. 1, 1995, pp. 39-40.

[10] T. S. Hudson, S. N. Subramanian and R. J. Allen, "Determination of Pantothenic Acid (and Its Alcoholic Analogue Dexpanthenol), Biotin, and Vitamin B12 (Cyanocobalamine) in Nutritional Products," Journal of the Association of Official Analytical Chemists, Vol. 67, 1984, pp. 994-998.

[11] S. S. Nag and S. K. Das, "Identification and Quantitation of Panthenol and Pantothenic Acid in Pharmaceutical Preparations by Thin Layer Chromatography and Densi- 
tometry," Journal of AOAC International, Vol. 75, 1992, pp. 898-901.

[12] J. Karhan, Z. Ksander, Z. Srank and K. Koblas, "Determination of Panthenol and Tocopherol in Medicaments by NMR Spectroscopy," Cesk Farm, Vol. 53, 1986, pp. 392-395.

[13] M. A. M. Shehata, M. A. Sultan, S. M. Tawakkol and L. E. A. Fatah, "Spectrofluorimetric Method for Determination of Panthenol in Cosmetic and Pharmaceutical Formulations," Saudi Pharmaceutical Journal, Vol. 12, 2004, pp. 29-34.

[14] O. A. Zaporozhets and L. Y. Tsyukalo, "Determination of Fluoride and Oxalate Using the Indicator Reaction of $\mathrm{Zr}(\mathrm{IV})$ with Methylthymol Blue Adsorbed on Silica Gel," Analytica Chimica Acta, Vol. 597, No. 1, 2007, pp. 171177. doi:10.1016/j.aca.2007.06.029

[15] K. Shimada, T. Shimoda, H. Kokusen and S. Nakano, "Automatic Microdistillation Flow-Injection System for the Spectrophotometric Determination of Fluoride," $\mathrm{Ta}$ lanta, Vol. 66, No. 1, 2005, pp. 80-85. doi:10.1016/i.talanta.2004.09.026

[16] D. G. Themelis, P. D. Tzanavaras and H. D. Tzanavaras,
"Simple, Rapid Reagent-Injection Spectrophotometric Determination of Fluorides in Pharmaceutical Formulations," Journal of Pharmaceutical Biomedical Analysis, Vol. 25, No. 5-6, 2001, pp. 971-976. doi:10.1016/S0731-7085(01)00373-9

[17] D. G. Themelis and P. D. Tzanavaras, "Simultaneous Spectrophotometric Determination of Fluoride and Monofluorophosphate Ions in Toothpastes Using a Reversed Flow Injection Manifold," Analytica Chimica Acta, Vol. 429, No. 1, 2001, pp. 111-116. doi:10.1016/S0003-2670(00)01271-X

[18] R. Lipka, M. Sobczak, K. Stanis, S. O. łdowski and M. Jarosz, "Determination of Fluoride Impurities in Leuprolide. Comparison of Analytical Methods," Microchemical Journal, Vol. 65, No. 1, 2000, pp. 51-58. doi:10.1016/S0026-265X(00)00028-X

[19] J. A. Nasr, Master's Thesis, Mansoura University, Mansoura, 2005.

[20] G. H. Lu, Q. L. Wang, X. G. Wu, T. Zhan and X. Yao, "Polarographic Determination of Trace Fluoride in Foods," Food Chemistry, Vol. 66, No. 4, 1999, pp. 519-523. doi:10.1016/S0308-8146(99)00091-6 